\title{
MAGPIE UPS AND DOWNS
}

MONTANA FISH AND GAME DEPARTMENT INFORMATION BULLETIN NO. 3

\section{By Robert L. Brown}

\section{Predator Investigations Biologist}

Convinced that magpies make better villains than heros, Montanans have engaged in control efforts of one sort or another since the birds were used as watch dogs by the Indians. In recent years, however, as magpies continued to maintain their numbers in the face of obviously ineffective control programs, an evaluation seemed in order not only of the bounty method used for control, but of what was involved in the control of a population.
How many magpies on a land area produce how many more? And how many survive to repeat the life cycle? The answers to these questions should describe the natural forces that break down artificial control measures and should help determine whether or not there is a need for control programs.

An investigation aimed at finding these answers was begun in 1956 under the direction of Dr. John Craighead, Leader of the Montana Cooperative Wildlife Research Unit.

FIG. 1

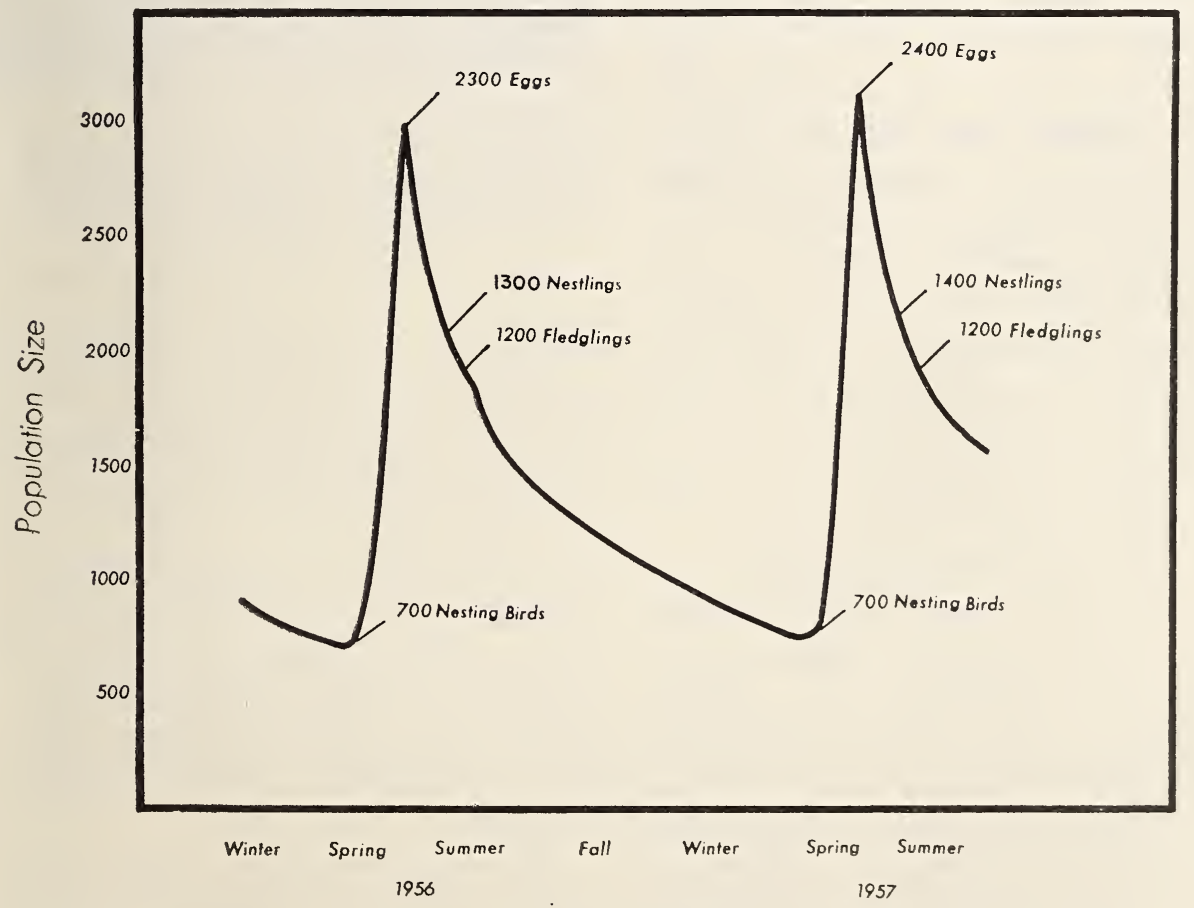

Changes in Magpie Population on 6.3 Square Mile Study Area in Western Montana 
During the two-year magpie study on a six square mile area in the Bitterroot Valley, over 800 nest histories were obtained, 1,371 magpies were leg banded, 771 color marked and 831 live trapped.

Wildlife populations have their ups and downs, and magpies are no exception to the rule. Changes in the Bitterroot magpie population studied are shown in Figure 1. Though there were seasonal fluctuations in numbers, each spring the populations dropped to the same level without assistance from organized $\mathrm{c} \circ \mathrm{n} \mathrm{trol}$ programs.

With a reproductive potential of over 330 percent, 700 magpies on the six square mile area in 1956 succeeded in increasing their numbers during the nesting season by 1,200 or 170 percent. Farm boys, adverse weather, disease, great horned owls, hawks, crows, pine squirrels, weasels, storlings and conflict between the magpies themselves combined to cut possible reproduction in half during the nesting season.

Proponents of control programs who are convinced that a need exists for doing something about potential magpie increases commonly fail to consider these losses which normally occur during the nesting season.

A magpie's life may suddenly end in many ways after he has survived the nesting season. Great horned owls, for example, with rapidly growing young to feed, readily take advantage of the new source of magpie protein. The extent of such predation was determined during the study by tethering young owls on the ground below their nests. Both

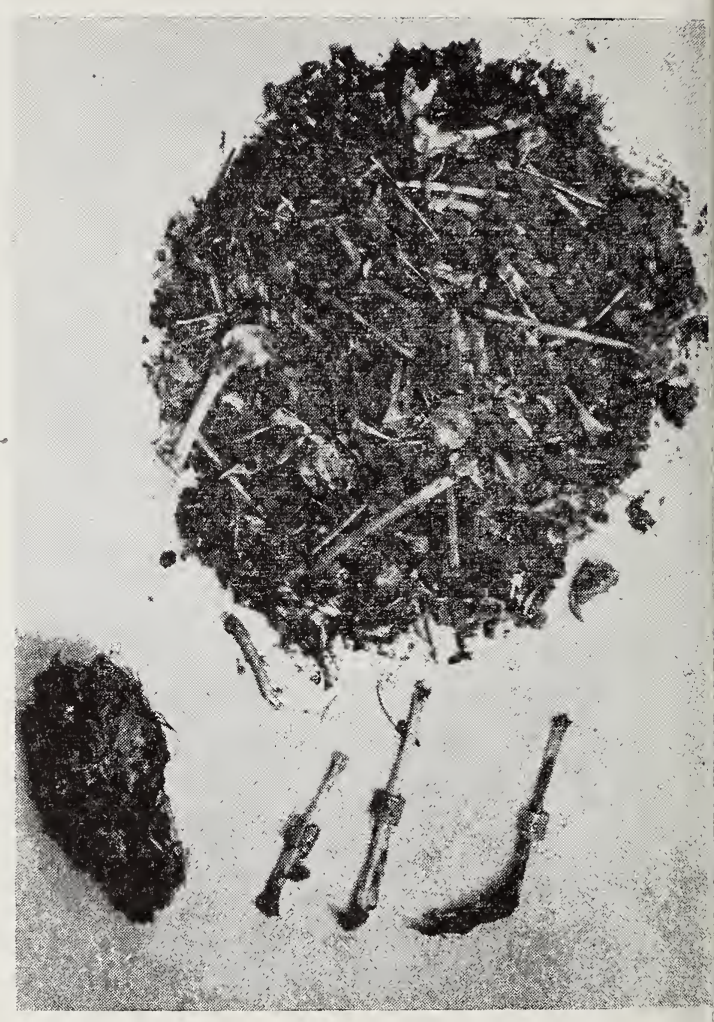

Great horned owl pellet showing the usual composition of regurgitated bone fragments, hair and feathers. This pellet represents an owl's evening meal of three banded magpies and a meadow mouse.

-Photo by Hector Lacasse

adult birds continued to feed and protect their young. Thus, the collection and analysis of food remains and pellets showed what the young owls had been fed. In this way it was found that 57 magpies were included in the food items of eight young owls during three weeks of each nesting season. Few people appreciate the role great horned owls play in reducing annual magpie surpluses.

The actions of many magpie eliminators, however, combine to hold the population in check. Thus, with- 
out bounties or organized control projects in effect the annual population surplus met various fates. By the following nesting season the population again numbered close to 700 magpies and the nesting cycle with a similar survival pattern was repeated.

\section{Why Not Bounties?}

Why the bounty system has failed to control magpie populations over the years may be illustrated by findings from the Bitterroot study. The most economical time to control this population on six sections of irrigated farming and grazing land would be in early spring when 700 (the lowest number of magpies during the year) are present. With a ten cent bounty only $\$ 70$ would do the job. Or would it?

So far, no one has come up with a way to remove the widely dispersed, seasoned survivors at a cost of ten cents each. Instead, bounty pressure is applied on the forthcoming crop of abundant and easy-to-come-by young. Sportsmen in this way may pay $\$ 20$ a section for a harvested crop of magpies when without bounties, natural predators and rural control activity accomplished the same end.

Now the question arises-what if more than the annual surplus is taken? Won't this decrease the population? Depending upon local conditions there may be cases where more than the annual production is removed; but soon the law of diminishing returns begins to take effect and as magpies become more scarce and wary, the increased effort neces- sary to continue their removal is not forthcoming. Thus, bountied populations may be stabilized somewhat below their normal levels. However, as depressed populations tend to have higher reproductive and survival rates, a bountied harvest may even increase the annual production.

Failings of the bounty system as a magpie control measure have been widely recognized. Although many sportsmen's organizations engaged in this activity in past years, the number dwindled to only six in 1958.

Realizing that this bounty program could not be justified solely on its public relation merits, the State Fish and Game Commission in November of 1958 rescinded its order which made matching funds available to sportsmen's organizations for the payment of bounties on magpies and crows.

\section{Local Pest or Damage Control}

Winter concentrations of magpies around farm buildings or livestock feeding areas may become a considerable nuisance to farmers or ranchers who find the pests everywhere but in front of the gun barrel. Farm lads and "machine shed inventors" looking for a solution through the years have designed many kinds of magpie traps with varying degrees of success.

A trap which has proved very effective was designed by Bill Woods, Predation Committee Chairman of the Western Montana Sportsmen's Association. The five-foot s qu are frame trap is covered with one-inch mesh chicken wire and has a funnel entrance at the ground level. Traps 


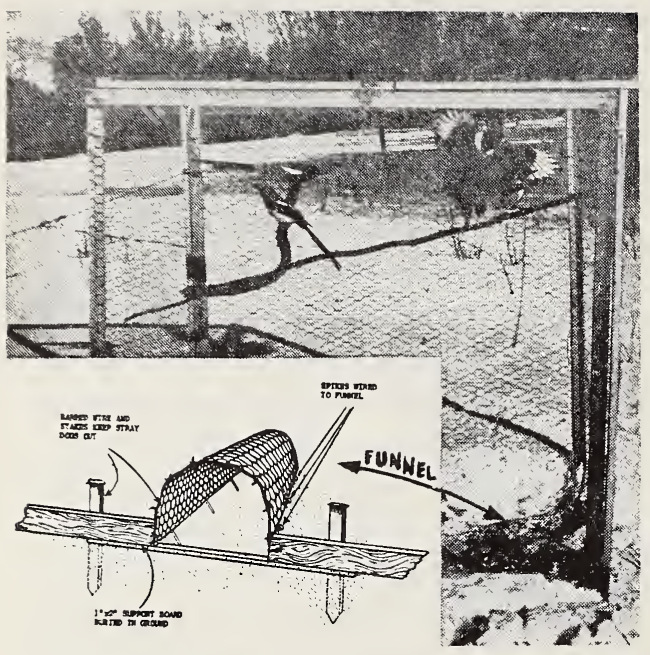

Portable magpie trap showing details of ground level entrance 16 inches in length.

-Photo by Bob Brown

of this type were used to capture over 1,000 magpies during the Bitterroot study. The entrance funnel which is made of one-inch chicken wire is the only part of the trap with critical dimensions. It is attached to the ground with stove wire and spikes as shown in the sketch. Baited with pork cracklings or meat scraps the traps proved most effective when placed between magpie feeding areas and roosting sites. A number of perches fastened in the upper section of the trap will increase its capacity and minimize the possibility of escape. From 20 to 30 magpies were often caught in the first or second setting; however, traps usually become progressively less effective with continued use in one place. Moving a trap as little as 50 feet has the effect of establishing a new set.

Live traps of this type may be used in densely settled farming areas because no danger is involved to human life or livestock. Cats and dogs may be caught, but are always found in better condition than is the trap. In order to prevent complications with dogs, the trap should be staked down and the outside of the entrance funnel encircled with a strand of barbed wire.

In sparsely settled areas where precautionary measures $\mathrm{may}$ be taken, poison is sometimes used in local magpie pest control operations. Baits composed of animal fat containing strychnine may be wired to poles and placed where there is minimum danger to livestock. Ranchers may obtain the assistance of government hunters where the use of poison is desired.

Sportsmen, farmers and ranchers in the Highline area may contact our Extension Trapper, Max Stone, at Wolf Point, if more information is desired on local magpie damage control through the use of traps.

Inquiries may also be directed to the Montana Fish and Game Department, Helena, Montana. 